\title{
Latour - Semiotics and Science Studies
}

\author{
Roar Høstaker
}

\begin{abstract}
The aim of this article is to study the relationship between Bruno Latour's theories and semiotics. In particular the article compares Latour's concepts to those of the linguist A.J.Greimas. From Latour's earliest texts in science studies onwards, semiotics has been a basic theoretical tool. As the article will show, Latour privileges the autonomy of language in order to avoid the ascription of substance to human and non-human actors. It is within this autonomous field that his general associology based on trials of strength can come into play. Furthermore, the article analyses Latour's theories concerning the gradual emergence of actors, circulation of references and technical mediation. Finally, the article tries to show how Latour's approach reaches a limit when it comes to the study of the settings of social action. A way out of this problem is sketched while at the same time remaining within a semiotic universe.
\end{abstract}

Key words: Bruno Latour, science studies, semiotics

It is well known that Bruno Latour's anthropology of science is to some extent influenced by semiotic theory. The use of concepts like actant, inscription, translation, modalities, shifting in, shifting out and regime of enunciation attest to this fact. The aim of this article is to show how most of Latour's theoretical views can be connected to semiotics, although this should not exclude other readings of his work. As I will show below, many of his analyses give actor-oriented or political explanations, as well as semiotic ones. On the other hand, agency has a central place in the semiotic theory with which I will compare
Latour's concepts: A.J. Greimas and his Paris school of semiotics. From his earliest texts on science studies (Latour and Fabbri, 1977) to his most recent ethnographic study of a court of law (Latour, 2002a), Latour always maintains semiotics as a basic theoretical tool. Greimas's works usually constitute a majority of his semiotic references, hence my interest in this article to study this connection. In a way, we might say that I am trying to read Latour's texts in the light of Greimasian theory in order to analyse some of the presuppositions of Latour's theories and to assess their strength and weaknesses. 
The place of Latour's anthropology of science within the general framework of science studies is, to a considerable degree, taken for granted in this article. I will, however, refer to some of his disagreements with his colleagues. The symmetrical principle of explanation of scientific facts introduced by Bloor (1976) and Barnes (1977) gave impetus to much of the work in this field during the $1980 \mathrm{~s}$ (cf. Cussins, 2000 for a general survey), but Latour has expressed much unhappiness about this principle. He maintains that it introduces a new asymmetry by giving priority to social explanations and hence underrates the agency of non-humans. Latour's solution is to introduce a principle of a general symmetry by which both objects/nature and society are explained simultaneously. When a new scientific fact enters the world, not only has nature changed, but also society and the social actors (Latour $1987 ; 1993 a)$. Over the years this view has led to much controversy (Schaffer, 1991; Collins and Yearley, 1992; Callon and Latour, 1992; Bloor, 1999a; 1999b; Latour 1999a).

This is not the occasion to follow up this polemic, but one of the subjects of this article is to show how Latour himself privileges the autonomy of language in order to be able to conceptualise a general symmetry. This opens the way for a fusion of actor-theory and semiotics in a general 'associology'. This situation of semiotics in his theoretical project is then followed by a close reading of his texts and especially the version of his 'translation model' from the 1990s. The notion of a 'translation model', however, is used only as a form of shortcut to summarise some of his anthropology of science. I will then try to show the limitations of his approach when it comes to discussions concerning the convergence and divergence of action. Latour's anthropology of science tends to encapsulate itself around case studies in order to avoid the ascription of substance or competencies to human or non-human actors. Finally, I try to sketch some ways out of these problems, but without leaving the world of semiotics.

\section{Latour and Semiotic Theory}

In a few texts Latour has himself commented upon the relationship to semiotics and its importance for his theories. Structural semiotics established language as a middle-field between nature and society, and Latour is critical of the tendency in much (French) theory to isolate this area completely from the world. Discourses do not speak themselves or texts do not write themselves. Nonetheless, he maintains that the autonomy of language must be respected since this area is the only place where we can avoid the twin perils of naturalism and social context (Latour, 1993a: 62-65; 1993b: 130-131; Crawford, 1993: 264). Actors, both non-human and human, can more freely be constructed on a joint plane of immanence. Within this autonomous conception of language natural and social entities can never be given a specific substance. To do so would be to interfere in the realm of the actors themselves. A general symmetry is thus possible, and it is on this plane that Latour's general 'associology' can come into play (cf. Crawford, 1993: 264). The latter is described in some detail in the philosophical précis Irreductions, printed as the second part of The Pas- 
teurization of France (Latour, 1988a: 153236). At the outset, Irreductions presents a principle of irreducibility: "nothing is, by itself, either reducible or irreducible to anything else" which is meant as a forewarning that there are no inherent truths. The second major principle is "whatever resists trials is real" (Latour, 1988a: 158). Everything can increase or decrease in reality through the force gained or lost by trials of strength.

'Trials of strength' was a central theme of the laboratory studies within the field of science studies in the 1970s and 1980s, and the ambition of Irreductions was to generalise this principle to an ontological level. Basic entities (often called actants) gain strength by associating with other entities. In this way they might resist some entities and form joint vectors of force with others (Latour, 1988a: 160). This is the basis of Latour's constructivism. But this 'associology' comes from a 'crossing' not only with semiotics but also with actor theory; the actor-based social theory Latour most frequently refers to is ethnomethodology. Although it may sound otherwise, it is not far from Greimasian semiotics because Greimas' theory of narratives contains its own theory of agency (cf. below). Furthermore, Latour points to a common research stance between semiotics and ethnomethodology: "Semiotics is the ethnomethodology of texts. Like ethnomethodology, it helps replace the analysts prejudiced and limited vocabulary by the actor's activity at world making" (Latour, 1993a: 131).

Both semiotics and actor theory seem to fuse into Latour's associology, and something that may be bewildering is the fact that he sometimes gives actor- oriented explanations in his texts, while at other times his explanations are semiotics-oriented. Many of Latour's most read texts from the 1980s emphasised actor-oriented explanations (cf. Latour, 1983; 1987) and his associology based on trials of strength has been much criticised. It was claimed that Latour portrayed science as though it were composed of expressions of political processes: a sort of generalised Machiavellianism or even worse - for Latour everything is war! (Haraway, 1997: 33-34). In the 1990s Latour tried to accommodate his views to some of this critique by introducing concepts inspired byWhitehead (Latour, 1996a; 1999b), and some of his dissatisfaction with Irreductions in the early 1990s came from the dangers of establishing a new meta-language (Crawford, 1993: 265). Scientific concepts, either from the social or the natural sciences, usually form an observation language that in many ways 'replaces' the entities it studies. Latour wanted to form an infra-language, whose role is to indicate only the relationship between entities, without 'touching' the objects themselves. Nonetheless, he seems to proceed in a way that is faithful to the essence of the principles of Irreductions (Crawford, 1993:266). During the 1990s and onwards, semiotics has continued to hold a central place in his theoretical formulations.

What form of semiotics does Greimas represent? Greimas's school was one of several different attempts in the 1950s and 1960s to develop a scientific approach to the analysis of language and texts. This usually included a rigorous theoretical apparatus in order to unveil the underlying structure of texts, or even of the wider discourse. This could be 
done through a systematic reduction of the diversity of texts into a small number of functions or elements. A major aim was to make the structure of the texts plain without any recourse to the intuition of the reader or the intentions of the author. The centre of attention was the texts themselves and the discourse of which they were a part. Greimas and his colleagues held that language should be studied both as system (along the paradigmatic axis) and process (along the syntagmatic axis). His main strategy in the analyses of language as system was to take utterances and terms (lexemes) and divide them into minimal units of signification - called semes - on an elementary level of signification. On this elementary level, semes form sememes, which is a composition of semes for a given term in a given context (Greimas and Courtés, 1982: 278-279; Greimas, 1983: 50-55). In this way the analysis of meaning can be constructed from elementary 'building blocks'. On the other hand, language as process is studied by Greimas and his colleagues as narratives (cf. Greimas, 1983; Hénault, 1979; 1983), and it is in this narratology we can find many of the parallels to Latour's observation language.

\section{The Translation Model}

Latour's associology, described in Irreductions, and developed in different directions since, forms an observation language for his ethnographic studies. His research strategy has been similar to much constructivist science studies: to follow how scientists and engineers make scientific or technical objects become real and how these scientists or engineers at the same time, change both themselves and the social collective (Latour, 1987; 1988a; 1996b; 1999b; Latour and Woolgar, 1986). Many of the studies from the 1980s described these processes in the idiom of agency or rather in terms of political or military mobilisation: "We study science in action and not ready made science and technology" (Latour, 1987: 258) and “... everything is involved in a relation of forces..." (Latour, 1988a: 7). From the 1980 s the concept of translation seems to summarise much of Latour's associology, and in an early article the following definition of translation is given: “... all the negotiations, intrigues, calculations, acts of persuasion and violence, thanks to which an actor or force takes, or causes to be conferred on itself, authority to speak or act on behalf of another actor or force" (Callon and Latour, 1981: 279). When an actor speaks of 'us', he or she is translating other actors into a single will of which the actor becomes a spokesperson.

Although actors are defined as actants, to give them a Greimasian flavour (Callon and Latour, 1981: 308, n.8), the concept of translation was developed by reference to Michel Serres (1974) and his $L a$ Traduction (cf. Callon and Latour, 1981: 308, n.6). But Serres is more engaged with the substance of scientific theories than Latour and his colleagues are. Serres's topic is 'ready made science' rather than 'science in the making', to use the lingo of late 1980s Latour (1987). Serres can use a concept from one field to analyse concepts from another. Unlike Latour, he seems less concerned with the development of a particular observational language for the study of scientific and technical research. Latour's observation language is, on the 
one hand, informed by notions of interests, alliances, enrolment, spokespersons, and strength. ${ }^{1}$ On the other hand, this observation language is formed by narrative theories.

However, what makes the notions of translation become an observational language? When Latour sets out to study how scientists and engineers construct their objects he has to describe them somehow, and he has set limits on the way this should be done. Anyone embarking on such a study should not "use culture, the content of science, or discourse as the cause of the phenomenon" (Crawford, 1993:263). We should not use nature to judge culture or discourse, and similarly, we should not use culture or discourse to judge nature (Latour, 1993a). In short, he advocates an agnostic stance in relation to the evaluation of the substances of the different disciplines constructing objects, whether these concern science, discourse or culture. In his case studies, Latour can leave judgements of substance to the actors themselves. They have to be: "left to their own devices. It's a laissez-faire sociology" (Latour, 1996b: 170). This is the basis for Latour's affirmative view of science, culture and discourse. His solution is to describe the forms or types of activities in which the actors are engaged in the translation process, whether these actors are people, objects or literary devices.

This is a solution quite parallel or analogous to the one chosen by Greimas. One of Greimas' starting points was Louis Hjelmslev's (1993) phonological model of language in which the Saussurean model of the sign is transformed. Hjelmslev distinguished between two parallel planes of language - that of ex- pression (signifier) and that of content (signified). These planes presuppose each other reciprocally. In addition, within these two planes he distinguished between form and substance (Hjelmslev, 1993: §13). Substance in this context is usually understood as meaning or purport in as much as they are taken on by the semiotic form (Greimas and Courtés, 1982: 322). If we, for example, take the phrase "the GRF hormone can cure dwarfism" ${ }^{2}$, this phrase can be expressed phonetically in different ways even by native English speakers - it varies in phonetic substance - but it has to conform to some sort of sound pattern and syntax in order to be understandable (form of expression). Similarly, a fundamental meaning of the phrase can be laid bare (form of content), and this meaning is given a substance within particular discourses. The phrase can be treated as a truth claim within biochemistry, an ethical or political question. These substantial matters cannot be decided by linguists, but have to be left to the actors themselves. The form (of expression and content) is necessary for the substance to be part of the signification, but the substance is variable and taken by itself it is amorphous.

For Greimas and his colleagues this division serves as a way to determine the object of linguistics to include only the form of the expression or of the content (see Figure 1). The substance is part of an indeterminate domain for the semiotician. The reason why the semiotician can say something about signification is that the form organises itself into systems of relations (cf. Hénault, 1979: 2829). It is not my intention to claim that Latour adopts this model, but by limiting himself to the forms of activities he 
introduces an indeterminate domain to the anthropology of science. This is a domain he leaves to the actors themselves.

In the following I will show how Latour develops the 'translation model' from the late 1980s and during the 1990s with reference to semiotics in general and Greimas in particular. I divide this analysis into three different (but related) topics: 1)how actants gain competence and emerge as actors through trials of strength, 2)how science 'loads' the world into discourse by circulating reference, and 3)how this whole process produces a collective of humans and non-humans.

\section{From Performance to Competence}

Many of Latour's texts are concerned with the question of how scientific ob- jects come into existence. In ways similar to other researchers in science studies, his answer is through trials and these trials usually start in a laboratory. But how are objects defined within such trials? First, the object is often only described by what it does. It has become a 'name of action' (Latour, 1993b: 136; 1999b: 119), or else "the 'thing' is a score list for a series of trials" (Latour, 1987: 89). We know what it does, but not yet what it is. This situation does not last long however, because each performance presupposes a competence which retrospectively explains why the object withstood the trials (Latour, 1987: 89). By being ascribed a competence, the object becomes an actor in the full sense (Latour,1999a: 122), it has gained a substance. This argument seems to rely on concepts from Greimas's analysis of narrative structures. The object is first an

Figure 1. Hjelmslev's model of the sign following Hénault (1979:28).

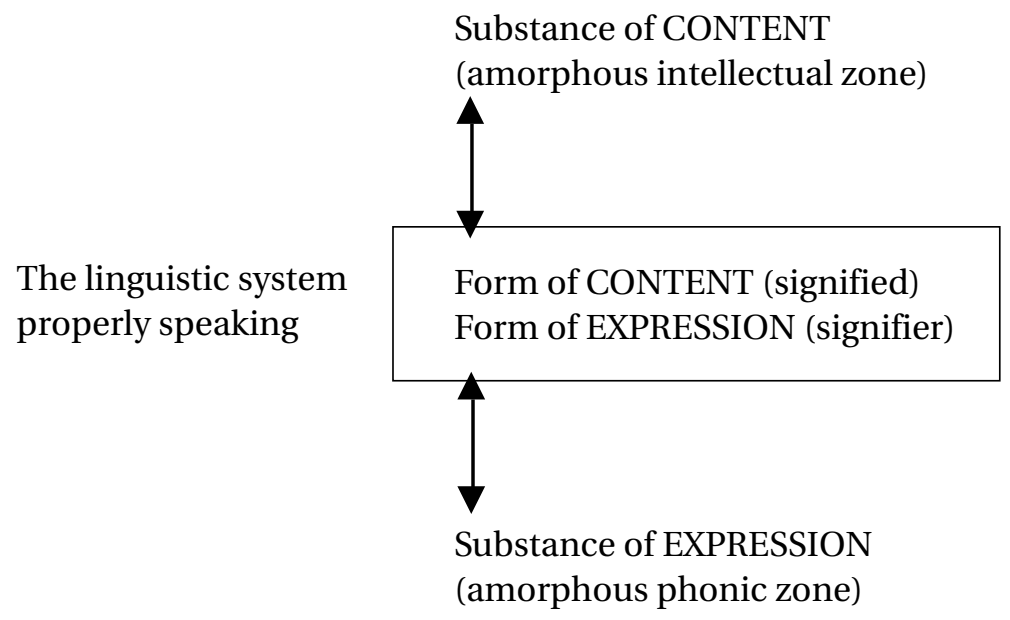


actant defined as "that which accomplishes or undergoes an act, independently of all other determinations" (Greimas and Courtés, 1982: 5). Only gradually does it become an actor by virtue of being invested with one or more roles.

Greimas based much of this work on Vladimir Propp's study of 100 Russian folktales (Propp, 1968 [1928]). Propp formulated 31 different functions to describe situations in these folk-tales. Greimas condensed and generalised Propp's schema during the 1960s and 1970s and gave different versions of a narrative schema in which a subject lacks a certain object (understood in wide terms). In the folktale the object might be a person or thing missing after a misdeed by a villain. A sender enters a contract with the subject (receiver) in order to liquidate what is missing. In the folktale the sender is often a person of authority from the social hierarchy (queen, king, mother, father) conveying an obligation upon the subject (Greimas, 1983; Hénault, 1979). The sender delegates a task to the receiver-subject and (often) sanctions the results of the action. The sender possesses some knowledge that he transmits to the receiver and he also frames the action. What makes a text a narrative text is, according to this theory, a state of dispossession or possession of some valued object leading to some action to produce the opposite state of dispossession or possession (Hénault, 1979: 145).

During the 1970s Greimas transformed the narrative schema further by concentrating on the relationship between the subject and the object as the principal actants of transformations. Utterances about the relation between a subject and an object were seen to take two basic forms - either an utterance of state (être) or an utterance of doing (faire). The justification for this theoretical articulation was that it allowed for a unified conceptualisation of descriptions and transformations (Hénault, 1983: ch.2). In syntagmatic chains utterances will take other utterances as their object and modalise them. When an utterance (of state or doing) governs another utterance (of state or doing), the first utterance is said to be a modal utterance while the second one is a descriptive utterance (Hénault, 1983: 55-61). When an utterance of doing modalises an utterance of state we have narrative performance. In the phrase "Eve bought a red dress" the action (buying) changes the state of Eve from a state of non-possession to a state of possession (of the dress). Performance amounts to the realised action in narratives. This realisation, however, presupposes the existence of some virtuality or potentiality for action. In other words, some state must lead to this or that form of doing. The subject in the phrase (Eve) must have a certain competence to do what she does. Greimas and colleagues distinguish between four modal values of competence. The subject can be seen to have knowing (savoir) about what to do, to be wanting (vouloir) to do something, to be obliged to or have to (devoir) do something, and to be able to (pouvoir) do something (Hénault, 1983: 55-61).

Typically a hero acquires different forms of competence during the course of a story ${ }^{3}$, but this competence is acquired before the hero's actual performance. According to Latour, however, this relationship is quite the opposite in scientific texts: performance comes first, then competence. In an analysis of Louis 
Pasteur's (1922) famous article 'La fermentation apellée lactique’ from 1857, Latour shows how, quite early on in his experiments, Pasteur identified a 'gray matter' as the substance that would play the major part in further experiments. In a further couple of pages he has identified this gray matter as a plant-like entity similar to the brewer's yeast that he had previously studied (Latour, 1993b). The competence - its substance of being a plant-like entity - is gained after a series of performances and is ascribed retrospectively. The potential of the yeast to start a lactic fermentation is, however, only valid under certain circumstances.

Latour's use of semiotic theory in this connection may be described as a bit unorthodox. An 'actantial' analysis of a scientific text like Pasteur's in a more Greimasian vein would probably have concentrated on a play of possession and dispossession of an object. The lack of knowledge of the causes of lactic fermentation described early in Pasteur's (1922: 5-6) article could be defined as the absence of a cognitive object. This also presupposes a knowing or cognitive subject formed by the inscribed author - the enunciator - in different ways. The aim of a scientific article in this view would be to liquidate the lack of knowledge and to gain possession of the object (cf. Bastide, 1981). This is a formula that would have gone counter to the Latourian notion of a symmetrical description of human and non-human actors.

\section{Circulating References}

A scientific article like Pasteur's presupposes that it is about something happening or being outside the text. If Pasteur as a scientist is going to be accepted as a truthful spokesperson for the ferment, his claims have to correspond to some activity in a glass jar. This is usually called the problem of reference in science: how do words on a paper refer to something taking place somewhere else or even in the past. The realist theory of science, so much part of our common sense, presupposes a fundamental discontinuity between word and world. Our words are mere descriptions or depictions of a not really knowable real world. Latour, on his side, holds that this part of scientific activity is best described as a circulation of reference (Latour, 1999b: 24). Something that re-presents the real is transformed into something transportable, but a trace is maintained that is immutable and some information is kept constant (Latour, 1988b: 21; 1999b: 58).

We can follow an example from Latour's participation in a pedological and botanical fieldwork in Boa Vista in Brazil. The group of scientists was studying a border area of the tropical rainforest and the savannah. Before they got down to work there was only undifferentiated forest and savannah. They could, of course, have described the forest or the savannah after having walked around in it. This is something that has been done many times in literature. The scientific enterprise, however, presupposed the establishment of a systematic reference to the object under study. This was obtained by the group first by dividing the area into numbered squares and then by taking samples of leaves and soil within each square. All samples were numbered and thus linked to their particular square. The soil samples were collected in a frame - the pedo-comparator mimicking the square structure of the 
area. The pedologists thereby obtained a synoptic representation of the soil in the area by this organisation of the lumps of earth. This device made it possible for the pedologists to assess the qualities of the soil at a glance and to enable the production of a graphical representation of the soil in the area. Later these samples were moved to Paris for further analysis and the results entered the scientific literature in the form of reports and papers. In this way the pedologists turned themselves into (scientific) spokespersons for the rainforest in Boa Vista (Latour, 1999b: ch.2).

An important point in this context is that the world can nowhere be seen apart from words, although the world is, of course, much more than words. If we limit ourselves to the non-scientific description, we can sense the forest, but we cannot produce signification about it (even in our thoughts) without adapting linguistic form to substance. In the research enterprise this is even clearer. When the researchers divide the area into numbered squares this is carried out by means of the forms found in geometry and arithmetic. When the researchers collect samples of the soil, the samples are not just earth, but, within this endeavour, they have taken on the form given to them by the researchers. They have taken on a significance beyond being just pieces of earth and have become representatives of some part of the area. They re-present the forest, and these lumps of earth can again be re-presented in the graphic table and the graphic table can be re-presented by descriptions in texts. (Latour, 1999b: ch.2).

Interpreted in semiotic terms this process of collection and re-presenta- tion of the forest and the savannah shows the process by which a science produces its internal referent. Each step of the re-presentation involves the cognitive activities of the enunciator (the researchers) through successive steps of shifting out by which they frame and stage the object they want to say something about (Latour, 1999b: ch.2; cf. Greimas and Courtés, 1982: 87-91, 259261). In fiction texts, shifting out is a technique used by the author (the enunciator) to move the reader's attention away from himself/herself and out to some action going on at another place, another time and concerning someone else (Latour, 1988b: 5). In this way an impression of realism is produced by the constraints that this shift has placed upon the actors. In scientific texts, this 'reality' or 'truth effect' is produced quite systematically. If we return to our example, we find, first, the shifting out from the enunciator to the frame of the geometrical pattern, then from these numbered squares to the samples of earth, from the samples to the pedo-comparator and from this device to the graphical drawing and from the graphical drawing to a written summary. The enunciator can at each step, without problems, move back from one or more of the frames - shift in - and say something about the condition of the forest and the savannah in Boa Vista (Latour, 1999b: ch.2). Shifting in is the opposite operation of shifting out and moves the attention back to the enunciator or some other 'I' in the text (Latour, 1988b: 6; Greimas and Courtés, 1982: 100-102). For each step in the chain of outward shiftings, something is delegated the task of re-presenting the object the enunciator really wants to say something about. 
However, this process of delegation depends at each stage on the relevance and the accuracy of the 'framing' made by the enunciator. It is this 'framing' that allows the sciences to claim that they speak about an external referent and not just an internal one. For Latour, however, every notion of an external referent is meaningless ${ }^{4}$. Reference can only mean the chain of translations of internal referents. To what degree scientists speak truthfully about nature depends upon the quality of this chain (Latour, 1999a: 310).

A consequence of this view is that there is no known or knowable reality that is a non-linguistic reality. That does not mean that everything is language, but rather that science has become immanent to language. There is no place where reality can hide outside language; this view constitutes a rebuttal of realist epistemology. The rupture between word and world, assumed by realist epistemology, involves presuppositions of an undifferentiated background existing independent of human knowledge. When scientists propose some state of fact about the world, a common argument is that this factual entity has always been present, even before the fact. The fact, lying in a slumbering state, is potentially knowable by us, and when it is discovered it simply manifests its potency. The real hero is the entity itself and not the humans who describe it and make it possible for this knowledge to be formulated. In no other situation is this clearer than in scientific controversies. From a realist standpoint the production of an artefact is usually described in social terms while the acceptance of a fact is described as being the thing itself. Everything happens as if the reality of the beyond somehow confirms or denies the efforts of human beings in their study of nature (cf. Latour, 1987; 1988a; 1999a; Latour and Woolgar, 1986).

\section{From Local Events to the Collective}

We have so far studied how Latour describes quite limited and local events. However, the 'translation model' used by Latour is also usually understood to provide a more general understanding of the composition of the world. This is usually described in the idiom of political activism: mobilisation, enrolment, interests, alliances, and spokespersons. (Latour, 1999b: 194; Callon, 1986). In this way new technical objects gain or lose existence (Latour, 1996b), and through the enrolment of technical objects and other humans we build a collective and even a Hobbesian Leviathan (Callon and Latour, 1981). However, in Pandora's Hope Latour again describes the basic relationships between humans and technical objects in the idiom of semiotics, although this is not always obvious in the text (Latour, 1999b: 176-193). Here he is concerned with how humans and objects fold into each other. How is it possible for us to treat technical objects around us simply as silent intermediaries? This is the core question in what Latour calls the four meanings of technical mediation. These meanings and how they relate to Greimas's semiotics are examined below.

Latour's meanings of technical mediation can be compared to Greimas's narratology. We have already discussed how narrative performance is formed in the example "Eve bought a red dress". This transformation of Eve from the non-possession of an object to the pos- 
session of it may be analysed as a narrative programme (Greimas and Courtés, 1982: 245-246). Traditional narratives are full of such programmes and they may be nested within each other. Eve may, for instance, have to jump on a bus to get to the shop in order to buy the dress. To take the bus may be seen as an instrumental sub-programme necessary to achieve the ultimate goal; of course there may be many other sub-programmes. For his part, Latour calls them programmes of action. Technical mediation in its basic form takes place when someone wants to achieve something and, in order to fulfil this intention, takes up an object that will enable the achievement of this goal. The object may, for instance, be a tool and Latour here uses the same example as Greimas and Courtés: a monkey fetching a stick in order to get a banana (Greimas and Courtés, 1982: 246; Latour, 1999b: 181-182). This instrumental programme may be nested within other sub-programmes: the monkey has to sharpen the stick before use, for example. This forms the second meaning of technical mediation and makes it possible to compose elaborate procedures (Latour, 1999b: 180-183).

The third meaning of technical mediation concerns 'blackboxing': "a process that makes the joint production of actors and artefacts entirely opaque" (Latour, 1999b: 183). A technical object with its multiple sub-programmes is stabilised to such a degree that we rarely have to take the 'technicalities' into consideration. We only discover them when something breaks down. In Greimas's parlance this may be described as annex narrative programmes by which we delegate subordinate tasks to someone or something (Greimas and Courtés, 1982:
246). The act of delegation is important at this point as it involves the transfer of competence (Greimas and Courtés, 1982: 72). As Latour (1987) has shown earlier, the degree of blackboxing may be so complete that it leaves the realm of discourse entirely. This is the fourth meaning of technical mediation: the silent presence of an enunciator materialised (shifted down) in some object constraining other actors to comply. His example is the speed bump constraining a driver to reduce the velocity of the vehicle in order not to destroy the car's suspension (Latour, 1999b: 185-190).

These different meanings of technical mediation form the basis upon which we build our relationship with objects, how we receive new possibilities through them and how asymmetries between humans develop. In other words, the emergence of what Latour calls the collective of humans and non-humans. By delegation we transfer competence to non-humans. An important question in this context is what sort of competence is delegated? As we have seen above, Greimas distinguished between four different modal values of competence: knowing-how-to-do (savoirfaire), wanting-to-do (vouloir faire), having-to-do (devoir faire) and being-able-to-do (pouvoir faire). Following the lead of his colleague Madeleine Akrich, Latour analyses the competence involved in the relationship between actors (non-human or human) in technical assemblies according to the modal value of havingto-do. This is never made explicit; however, it is clear from the analyses of such assemblies as scripts (Latour, 1988c; 1992; Akrich, 1992; Akrich and Latour, 1992). When technical objects are constructed their makers inscribe some pro- 
grammes of action into them. Instead of talking about the function of a technical device, Latour prefers to say that a device prescribes some types of performance from other actors (humans or nonhumans), it proscribes others, and it allows or may afford others (Akrich and Latour, 1992: 261). In the speed-bump example, the bump may be said to translate the will of the road-works authorities to allow cars to drive on the road, but at the same time it prescribes a low speed.

These four categories represent the modal structure of having-to-do projected onto what Greimas called the semiotic square (cf. Figure 2) (Greimas and Courtés, 1982: 140-141). The semiotic square is a way to analyse the semantic relationship between opposi- tions, contradictions and complementarities. For example, those performances that are optional (afforded) are defined by a negation of those prescribed, but at the same time, they stand in opposition to those allowed. This opposition arises from the fact that optional actions are both non-obligatory and involve real freedom of choice, since allowed performances are limited by not falling into a category of proscription. At the same time, some optional performances may be proscribed ${ }^{5}$ and others not.

Different parts of a technical-social assemblage may be analysed as delegated competencies in this way, but competencies other than the "having-todo' are needed as well. Akrich and Latour also include what they call subscription

Figure 2. The modal structure of Having-to-do (devoir) with Latour and Akrich's concepts in brackets.

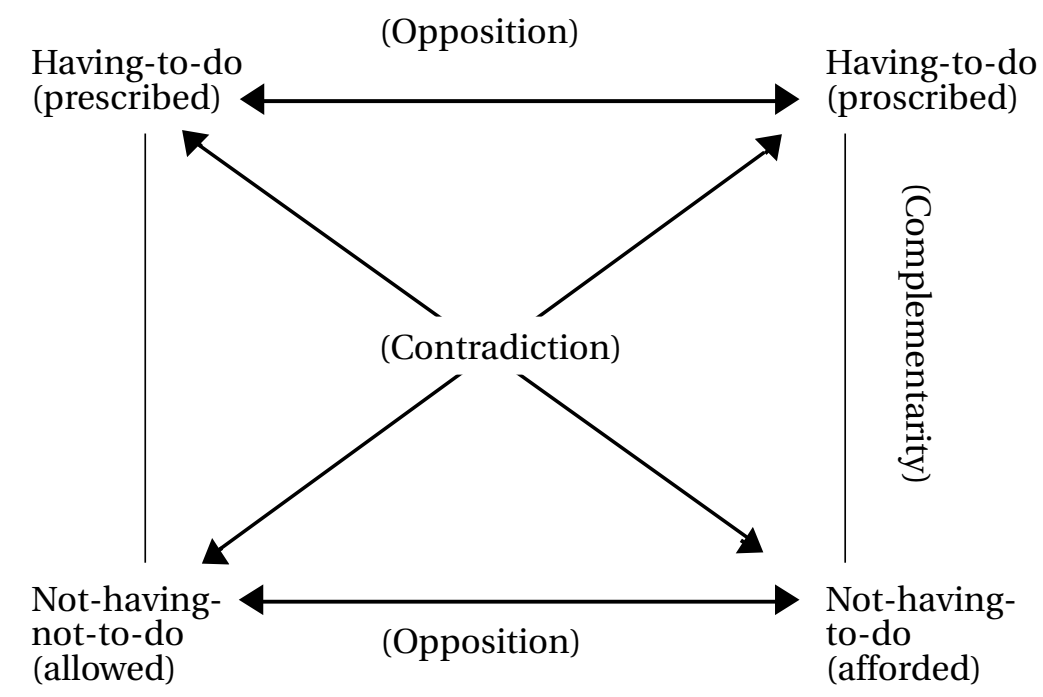


and its opposite, de-inscription, to describe the reaction of the anticipated actor to what is prescribed or proscribed to them. There is a gap or a possible crisis between subscription and prescription when the actor confronts a new setup. The actor may have his/her/its own anti-programmes and will not accept the given one. Furthermore, Latour and Akrich (1992: 261) use the notion of preinscription to describe the competence that can be expected from actors arriving at a given setting, competence that is necessary for the resolution of the crisis between prescription and subscription. The link to the Greimasian understanding of competence is not as clear in these instances as it is in the previous one, but the paired concept 'subscription/de-inscription' seems to be similar to Greimas' modal value of wanting-todo (and wanting-not-to-do), while preinscription seems to be similar to the modal value of knowing-how-to-do (Greimas and Courtés, 1982: 167-168, 372-373). For example, in order to operate an ATM, it is not only necessary to want to withdraw money (and to prefer the machine to a clerk at a branch of the bank), but you have to know how to insert your card, give up your pin-code, etc.

Changes in a technical-social assemblage usually involve a redistribution of competencies and performances of actors in a setting, and the distribution of competencies and performances in a given assembly can be de-scribed by an analyst. What is interesting in this context is that the concept of competence involves a virtual dimension since competence is a presupposition of the actual or realised performance. Latour, however, does not seem to accept the virtuality of competence in other ways than as an ascription of certain qualities. Ascription is an attribution process through which the origin of the activity of a given set-up is assumed to come from the set-up itself, for instance, after the activity has been black-boxed. Ascription is the final result of a scientific or technical object's successful creation - it has gained a substance. (Akrich and Latour, 1992)

\section{Limits to Latour's Approach}

I have so far presented Latour's anthropology of science in relation to narrative theory. In this section we will show how his approach reaches its limits in various ways. First of all, there are limitations to the way he constructs the context of his studies and the question of how convergence of action is produced.

The object of study for Latour is how human actors construct scientific facts; how they circulate references and make technical entities come into existence. His programme is to follow the actors and their activities. Traditional sociology would state that in order to do this, Latour would have to situate his actors carefully in a social context, and in some way, refer what they actually do to this context. This form of contextual explanation has been one of the main targets of Latour's critique of the social sciences. Within these sciences the acts of individual actors are often tied to social interests, social representations and general beliefs or other external determining causes. Realised acts are aligned with this pre-established context and suddenly the researcher has an explanation for why actors actually did what they did (Latour, 1996a: 199). Latour does not 
deny the existence of social context, but action cannot be explained by context. Nor does action reside as some potential, either outside or inside the actors, because we cannot know why actors really do what they do. These are forms of information we do not have access to. All presuppositions of access as to why actors really do what they do amounts to an intervention from something beyond our knowledge (Latour, 1988a: 18-19, 253; 1996b: 142-143, 154-155, 162-163, 167-168, 170, 199-200).

Latour solves the problem by analysing how actors involved in the same field or controversy link together and combine actors: "whom they endow with qualities, to whom they give a past, to whom they attribute motivations, visions, goals, targets, and desires, and whose margin of manoeuvre they define" (Latour, 1996b: 163). In this way social actors engage in contextualisation: they analyse and interpret their social context and direct their actions in relation to some part of this context. Social context becomes a resource for the actor in his/her production of agency. The different elements of the context can be made explicit in the same way as meaning is produced through the realisation of language: by inter-definitions (Latour, 1988a: 9-10). All these social actions are connected to the (inter-) definitions of meaning, and may thereby become the object of semiotic-based analyses. These different inter-definitions of meaning nonetheless throw us back to the particular utterance as the starting point for the analysis of a controversy or a field.

Latour's views seem to be similar to those of Greimas who distinguishes between explicit (or linguistic) context and implicit context. The implicit context is characterised as 'extra-linguistic' or 'situational' and can be important for the understanding of texts. However, it can only be called upon for semantic interpretation when it has been made explicit (Greimas and Courtés, 1982: 58). By studying social context through contextualisation Latour manages to make the social immanent to language. His critique of context-oriented sociology is highly relevant and especially its tendency to analyse the relation between context and individual, or structure and action, as a question of general causes having particular effects. In such explanations there is an outside that suddenly intervenes in the action. However, with the notion of contextualisation, Latour enters into the same difficulties faced by many practitioners of actor-oriented sociology. Since he depends upon the actors' own inter-definitions he is limited to the actors' own taken-for-granted world. He can make explicit many of the implicit notions in texts, but the analysis ends at, or stays within the realm of, what the actors have in common. This shared implicit world becomes a setting that he can describe, but whose own principles cannot be analysed (cf. Alexander, 1982) since they belong to another dimension. The result is a form of 'endogenization' where the setting closes itself around the events taking place (Chateauraynaud, 1991).

\section{Convergence and Divergence}

Another feature of context-oriented sociology is that it usually presupposes a superior or underlying level where the meaning of the multiplying actions of actors will converge. That is why general causes can lead to particular actions. 
Context understood as inter-definitions, on the other hand, leads us to another conclusion. The more texts we include, the more the context will diverge in different directions. While there might be centres where a certain degree of universality is produced, even these are actually local and particular (Latour, 1988a: 253). There is no superior or underlying level in Latour's theory. Everything is on the same plane and will pull in different directions. Nonetheless, in Latour's theories there is one sort of 'contextual' structure presupposing convergence; this is found in his concept of regimes of enunciation. Suddenly he can talk about a co-ordination by "sub-jected or preexisting structures” (Latour, 2002b: 143, my translation).

What is meant by enunciation? If we go back to Greimas and Courtés they define it in two ways as " a) the non-linguistic (referential) structure which underlines linguistic communication, or b) as a linguistic domain which is logically presupposed by the very existence of the utterance (which contains traces or markers of the enunciation)" (Greimas and Courtés, 1982: 103). If we follow the first definition we delve into discussions about the communication situation and its social and psychological context, which is the subject area studied by socio-linguists (among others). This is what forms the way we produce discourse from the outside of the given situation. Courtés and Greimas, however, stick to the second definition of enunciation in order to remain within semiotics. According to this definition enunciation becomes the domain of mediation that forms the process in which discourse is produced (Greimas and Courtés, 1982: 103-105). It governs the passage from lin- guistic competence to linguistic performance, and is an important part of the analysis of language along the paradigmatic axis.

Latour has identified only a few regimes of enunciation - the scientific, the religious, the political and the judicial. In order to speak scientifically, politically, religiously or judicially we have to do so in certain distinct ways. To speak scientifically we have to be able to produce circulating references by which our utterances (here and now) may be understood to represent an object (at another place) in nature. The problem arising when we speak both religiously and politically is the hegemonic position of the scientific regime of enunciation. The chain of translations forms a straight line and all other sorts of enunciation are valued according to this pattern. We tend to treat all forms of speech as information and especially as information without any mediation. In the latter case the chain of translation is collapsed into what Latour calls 'double-click information'. The truth or falsity of some utterance is thought to be easily verified by, for instance, a click or two of your computer mouse (Latour, 2002b; 1999c; 2002c). If every utterance is supposed to be verifiable in that way, most of our utterances will fail and we will inexorably be liars, cheaters and mystics. Latour's identification of a religious, judicial and a political regime of enunciation is hence an attempt to revive them and to protect them from encroachment by the scientific regime of enunciation and especially from 'double-click information'. To speak religiously therefore has nothing to do with representation and the transmission of information, but is a way to create a certain presence (Latour, 
1999c; 2002c) while to speak politically is to create the united representation of a multiplicity (Latour, 2002b).

The regime of political enunciation does not describe a line, but rather, a circle. A person trying to speak on behalf of a multiplicity forms it into a unit. In order to make the multiple into one, the representative has to claim autonomy while at the same time being obedient to the demands of the multiplicity. To speak politically is thus concerned with both how to produce unity (autonomy) and how to be faithful to the represented (heteronomy). This involves work leading to a circular movement between a situation of univocality and the dissolution of this unity in a situation of multivocality. If the work of mediation and representation is successful it will form a 'good curve' and a political group will be formed. However, it is an impossible task to make this combination of faithful representation and unity for action without distorting the immediate demands of the relevant multiplicity. This is why political enunciation is so full of circular and vague expressions, repetitive phrases and catchy words. From the viewpoint of 'double-click information' this is betrayal, but this 'betrayal' is an integral part of the political way of speaking. The representative should betray the multiplicity in order to give it one voice. What is important for Latour is to liberate political enunciation from being valued according to non-political criteria (Latour, 2002b).

Latour's use of enunciation seems clearly to conform to the linguistic definition, and to the fact that a regime of enunciation may be seen as a virtual structure pre-existing the utterance and coordinating it ${ }^{6}$. The different regimes sug- gest different subject-positions and different pre-existing competencies in the performer in order to speak truthfully within each regime. An important observation, however, is that a regime of enunciation is not based upon inter-definitions or the actors' own contextualisations, because this regime is a structure that exists $a$ priori, and the actors often unconsciously presuppose them. Here, Latour has suddenly left his own method of following the actors. However, a regime of enunciation avoids the trap of contextoriented sociology by not starting from a point outside the context, but from within it. Nonetheless, this concept amounts to a change of perspective in Latour's theories since the focus is not how actors make their own world, but how a world not of their own making over-determines how they express themselves (if they are competent performers). Latour (1993a: ch.2) provides similar preexisting structures in his analyses of modernity as a constitution governing how we distinguish between nature and culture, and similarly, the iconoclastic gesture by which we denounce fetishes of different kinds (Latour, 1996c; 1999b: ch.9).

The great difference between such Latourian structural formulations and context-oriented sociology, is that in Latour's formulations there are no general causes intervening from the outside and deciding what the actors say or do. The structures are positions offered us, and we can, at least to some extent, avoid them. However, a regime of enunciation or a similar structure is a historically constituted entity, but the extra-contextual relationships keeping it in existence do not seem to interest Latour. That would perhaps be to ascribe a given 
competence or substance to a particular (social or material or discursive) entity. In this case, he also seems to encapsulate his analyses within a given frame that cannot itself be studied.

\section{Critical Remarks}

A recurring problem with Latour's theories may seem to be the absence of or rather diminutive role given to a virtual dimension. The virtual may be understood in a linguistic sense as an existence "in absentia" (Greimas and Courtés, 1982: 371) and this form of existence characterises the language along its paradigmatic axis. A paradigm is a class of elements that can occupy the same place in a syntagmatic string, and elements can be recognised by an "either ... or" relation (Greimas and Courtés, 1982: 224). In the example "Eve bought a red dress", the dress could have been another colour, another type of garment, some other person could have made the purchase, or the transaction could have been different. The paradigmatic axis represents sets of possible combinations and the rules governing the combination of phrases will determine how we can express ourselves. Latour's main strategy of following the actors' construction of the world, may be seen as an overemphasis given to the syntagmatic axis and thereby always giving preference to the observable and actual over the principles governing the setting.

From the acknowledgement of the absence of an explicit virtual dimension in Latour's theories and to point at a possible solution is not straightforward. The difficult question is to understand the 'extra-contextual' relations governing a given setting. One possible solution without leaving the area of semiotics, is offered by Deleuze and Guattari (1984; 1987: ch.9) and their notion of the molar and the molecular as different levels of the social and the one overcoding the other ${ }^{7}$. The molecular concerns the active creation of multiple connections between liberated flows. All sorts of connections are in principle possible. On the other hand, all civilisations or societies imply a certain regulation and steering of these flows. This external regulation of 'mass action' is what Deleuze and Guattari call the molar. The regulation of flows is usually governed by the "political machine', which in modern societies is the state. The molar overcoding the molecular happens through a process by which a common content (signified) is connected to a given chain of expressions (signifiers). In this way the flow of expressions are 'locked' to a given signification.

Latour gives an example of how this process may work in The Pasteurization of France, in which he mentions that an important motivation for the scientific effort in France in the late 19th century was to avenge the war of $1870-1871$. Everything that made the French people stronger would make this goal more attainable (Latour, 1988a: 6-12, 16-19). Latour made this into a part of the setting in order to study how Pasteur transformed the field of hygiene, but what is clear is that the desire for revenge somehow produced a overarching meaning to very diverse scientific efforts. However, this desire cannot be used to 'look through' the motives of the actors or to reduce their actions to this project. Nonetheless, this setting must have imposed strong limitations concerning possible actions. In the same way as Pas- 
teur had to align his interests with the hygiene movement, he had to be a French patriot or nothing. The field of science in France was, in this way, overcoded by nationalism. A major point of Deleuze and Guattari is that the molar is of a different nature than the molecular and hence have to be studied in it own way. Latour's emphasis given to the molecular relations limits his approach.

Another avenue of critique can be opened in relation to Latour's agnostic stance in relation to the substance of scientific research and its social and environmental consequences (cf. above). The question is for how long the anthropology of science can isolate itself from the matter of science. By limiting his approach to what actors do, without passing judgements on their actions and their objects, a Latourian researcher may easily slip into a mode of acquiescence. As a research strategy, this agnosticism has been very fruitful, but Latour has recently tried to export it to the field of politics in order to "bring science into democracy" (Latour, 1999d). In the same way as his studies of scientific practices, his critique of political institutions concerns their form and not their substance. If he had engaged himself with the latter, he would have been forced to take into consideration the existing assemblages of political enunciation. Instead he limits himself to sketching new forms of representation and decision-making that include science and technology (cf. Latour, 1999d). However, this politics of nature has no direction. It is without substance and hence without any politics at all (cf. Caillé, 2001). In order to solve our ecological problems, the only thing he can offer is a rewriting of the rulebook of liberal democracy. In his at- tempts to be political Latour seems to have demonstrated another limit to his approach.

\section{Conclusion}

Latour's anthropology of science is original and interesting insofar as he has introduced a certain line of reflection into science studies and social theory in general. A part of this line of reflection is to make semiotic concepts operational in social science research. His analyses of circulating reference, the gradual emergence of scientific objects and of technical mediation is important in this connection. The limits of Latour's approach are not due to semiotics, but rather to his application of it. He has, to a high degree, limited his approach by giving preference to the observable and actual over the principles governing the setting. Or, in linguistic terms, he seems to prefer analyses along the syntagmatic axis to those along the paradigmatic axis. However, the concept of regime of enunciation seems to bridge some of this tension between the actual and the virtual. This also holds true for his analysis of the competencies of techno-social assemblages.

One consequence of Latour's preference for the actors' actual construction of the world, is the tendency of Latour's case studies to encapsulate themselves within a limited context. This can be avoided in other ways and still fall within a semiotic universe. I have tried to show this by introducing Deleuze's and Guattari's distinction between the molecular and the molar as two different levels and how the latter may overcode the former. Latour concentrates his efforts on the molecular level and he only 
touches the molar indirectly. Furthermore, the tendency of encapsulation may be exacerbated by his agnostic view of science whereby he does not allow himself to pass judgements on scientists and their substances. This principle is more than a methodological device for Latour and seems to isolate his anthropology of science from the world when he wants to do more than case studies.

\section{Notes}

1 Serres's understanding of interest also diverges strongly with the understanding within science studies (Callon, 1986: 186).

2 Taken from Latour 1987, Chapter 1.

3 Hénault uses Star Wars as an example:The young Luke finds a video message showing a princess in distress. This leads to the search for Obi Wan Kenobi (first acquisition of knowing to do as well as wanting). The latter reveals to Luke his origins and what he should do (first acquisition of having to do), but also informs him about the galactic struggle to come (second acquisition of knowing to do). Later the old man becomes the Mentor of Luke and instructs him in the practices of combat (acquisition of being able to do) (1983: 57).

4 Greimas, for his part, presupposes an external referent as an extra-linguistic reality. However, he is aware that all sciences (through their discourse) must build an internal referent (Greimas and Courtés, 1982: 259-261).

5 Although these cannot really be afforded in a technical system without destabilising it.

6 This is an interpretation of Latour's texts. The concept of regimes of enunciation is not really well developed by Latour. He only refers to it on a few occasions and most explicitly in 2002b.

7 I have chosen this alternative perspective because Latour claims to build upon the theories of Deleuze (Crawford, 1993: 263).

\section{References}

Akrich, M.

1992 "The De-Scription of Technical Objects." Pp. 205-224 in Bijker, W.E. \& Law, J. (eds.), Shaping Technology/Building Society: Studies in Sociotechnical Change. Cambridge, Mass. \& London: The MIT Press.

Akrich, M. \& Latour, B.

1992 "A Summary of a Convenient Vocabulary for the Semiotics of Human and Nonhuman Assemblies" Pp. 259-264 in Bijker, W.E. \& Law, J. (eds.), Shaping Technology/Building Society: Studies in Sociotechnical Change. Cambridge, Mass. \& London: The MIT Press.

Alexander, J.C.

1982 Theoretical Logic in Sociology. vol. 1: Positivism, Presuppositions, and Current Controversies. London: Routledge \& Kegan Paul.

Barnes, B.

1977 Interests and the Growth of Knowledge. London: Routledge \& Kegan Paul.

Bloor, D.

1976 Knowledge and Social Imagery. London: Routledge \& Kegan Paul.

1999a "Anti-Latour." Studies in History and Philosophy of Science 30(1): 81-112.

1999b "Reply to Bruno Latour." Studies in History and Philosophy of Science 30(1): 131-136.

Bastide, F.

1981 "La démonstration, Analyse de la structure actantielle du faire-croire" [The demonstration. Analysis of the actantial structure of making-believe] Documents de Recherche. Groupe de Recherches sémio-linguistiques, EHESS. 3 (28).

Caillé, A.

2001 "Une politique de la nature sans politique." [A politics of nature without politics] Revue du M.A.U.S.S, (no. 17): 94-116. 
Callon, M.

1986 "Éléments pour une sociologie de la traduction. La domestication des coquilles Saint-Jacques et des marinspêcheurs dans la baie de Saint-Brieuc" [Elements for a sociology of translation. The domestication of scallops and fishermen in the Bay of Saint-Brieuc] L’Année sociologique, 36: 169-208.

Callon, M. \& Latour, B.

1981 "Unscrewing the big Leviathan." Pp. 277-303 in K. Knorr-Cetina \& A.V. Cicourel (eds.), Advances in Social Theory and Methodology: Toward an Integration of Micro- and Macro-sociologies. Boston et al: Routledge \& Kegan Paul.

1992 “Don't Throw out the Baby With the Bath School: Reply to Collins and Yearly" Pp. 343-368 in Pickering, A. (ed.), Science as Practice and Culture. Chicago: University of Chicago Press.

Chateauraynaud, $\mathrm{F}$.

1991 "Forces et faiblesses de la nouvelle anthropologie des sciences." [Strength and weaknesses of the new anthropology of science] Critique, (no. 529-530): 459-478

Collins, H.M. \& Yearley, S.

1992 "Epistemological Chicken" Pp. 301-326 in Pickering, A. (ed.), Science as Practice and Culture. Chicago: University of Chicago Press.

Crawford, T.H.

1993 "An interview with Bruno Latour." Configurations 1(2): 247-269.

Cussins, C.M.T.

2000 "Primate Suspect: Some Varieties of Science Studies.” Pp. 329-357 in Strum, S.C. \& Fedigan L.M. (eds.), Primate Encounters: Models of Science, Gender, and Society. Chicago \& London: Chicago University Press.

Deleuze, G. \& Guattari, F.

1987 A Thousand Plateaus: Capitalism and Schizophrenia. vol.2. London: Athlone Press.

Greimas, A.J.

1983 Structural Semantics: An Attempt at a Method. Lincoln \& London: University of Nebraska Press.
Greimas, A.J. \& Courtés, J.

1982 Semiotics and Language: An Analytical Dictionary. Bloomington: Indiana University Press.

Haraway, D.J.

1997 Modest_Witness@Second_Millenium. FemaleMan”_Meets_Oncomouse'. Feminism and Technoscience. New York and London: Routledge

Hénault, A.

1979 Les enjeux de la sémiotique. [The stakes of semiotics] Paris: Presses Universitaires de France.

1983 Narratologie, sémiotique générale. Les enjeux de la sémiotique. tome II. [Narratology, general semiotics. The stakes of semiotics, vol.II] Paris: Presses Universitaires de France.

Hjelmslev, L.

1993 [1943] Omkring Sprogteoriens Grundlæggelse. [Prolegomena to a Theory of Language] Copenhagen: The Linguistic Circle of Copenhagen.

Latour, B.

1983 "Give Me a Laboratory and I will Raise the World" Pp. 141-170 in Mulkay M. \& Knorr-Cetina K. (eds.), Science observed, Perspectives on the Study of Science. London: Sage.

1987 Science in Action: How to Follow Scientists and Engineers through Society. Cambridge, Mass.: Harvard University Press.

1988a The Pasteurization of France. Cambridge, Mass. and London: Harvard University Press.

1988b "A Relativistic Account of Einstein's Relativity" Social Science Information 18: 3-44

1988c (Jim Johnson) "Mixing Humans and Nonhumans Together: The Sociology of a Door-Closer" Social Problems 35(3): 298-310.

1992 "Where Are the Missing Masses? The Sociology of a Few Mundane Artifacts." Pp. 225-258 in Bijker, W.E. \& Law, J. (eds.), Shaping Technology/Building Society: Studies in Sociotechnical Change. Cambridge, Mass. \& London: The MIT Press.

1993a We Have Never Been Modern. New York: Harvester Wheatsheaf. 
1993b "Pasteur on Lactic Acid Yeast: A Partial Semiotic Analysis", Configurations. Johns Hopkins University Press 1(1): 129-145.

1996a "Do Scientific Objects Have a History? Pasteur and Whitehead in a Bath of Lactic Acid." Common Knowledge 5(1): 7691.

1996b ARAMIS or the Love of Technology. Cambridge, Mass. \& London: Harvard University Press.

1996c Petite réflexion sur le culte moderne des dieux faitiches. [Small reflection on the modern cult of factish gods] Paris: Les Empêcheurs de penser en rond.

1997 “Socrates' and Callicles' Settlement - or The Invention of the Impossible Body Politic" Configurations. Johns Hopkins University Press 5(2): 189-240.

1999a "For David Bloor... and Beyond: A Reply to David Bloor's "Anti-Latour"“, Studies in History and Philosophy of Science 30(1): 113-129.

1999b Pandora's Hope: Essays on the Reality of Science Studies. Cambridge, Mass. \& London: Harvard University Press.

1999c “'Thou shalt not take the Lord's name in vain' - being a sort of sermon on the hesitations of religious speech", Res, (no. 39): 215-234.

1999d Politiques de la nature: Comment faire entrer les sciences en démocratie. [Politics of nature. How to bring the sciences into democracy] Paris: La Découverte.

2002a La fabrique du droit. Une ethnographie du Conseil d'Êtat. [The making of justice. An ethnographic study of the Conseil d'Êtat] Paris: La Découverte.

2002b Et si l'on parlait un peu politique? [What if we spoke a bit of politics?] Politix 15 (58): 143-166.

2002c Jubiler - ou les tourments de la parole religieuse. [Being jubilant - or the torments of speaking religiously] Paris: Les Empêcheurs de penser en rond, Seuil.
Latour, B \& Fabbri, P.

1977 "La rhétorique de la science. Pouvoir et devoir dans un article de science exacte." [The rhetoric of science. Beingable-to and having-to in an article of the exact sciences] Actes de la recherche en sciences sociales. (Fevrier): 8195.

Latour, B. \&Woolgar S.

1986 Laboratory Life: The Construction of Scientific Facts. Princeton, NJ: Princeton University Press.

Pasteur, L.

1922 "La fermentation apellée lactique" [The so-called lactic fermentation] Pp. 3-13 in Vallery-Radot, P. (ed.), Oevres de Pasteur. tome 2: Fermentations et générations dites spontanées. Paris: Masson et Cie, Editeurs.

Propp, V.

1968 [1928] The Morphology of the Folktale. Austin, Texas: American Folklore Society Biographical and Special Series. no.9.

Schaffer, $\mathrm{S}$.

1991 "The Pasteurization of France - B. Latour" Studies in the History and Philosophy of Science 22(1): 175-192.

Serres, M.

1974 Hermes III: La Traduction. [Hermes III: The translation] Paris: Les Éditions de minuit.

Roar Høstaker

Lillehammer University College

Lillehammer, Norway

Roar.Hostaker@hil.no 